\title{
Supply chain of some medicines in health facilities in Jos, Nigeria: post Federal Ministry of Health mapping survey
}

\author{
Ndidi C. NGWULUKA*, Ibironke M. AKINDELE, Nelson A. OCHEKPE \\ Faculty of Pharmaceutical Sciences, University of Jos, 930001, Nigeria.
}

Received 20 $0^{\text {th }}$ May 2020; Accepted $9^{\text {th }}$ September 2020

\begin{abstract}
The Nigerian health system is fraught with inadequate personnel, weak logistics systems and poor service delivery. The Federal Ministry of Health (FMoH) report on mapping of partners' procurement and supply management systems for medical products with its recommendations was evaluated. An assessment of Supply Chain Management (SCM) of health facilities as well as the different categories of personnel that manage them was conducted. The study indicated $79.5 \%$ of the facilities received free antimalarials, $46.2 \%$ received free ARV and $23.1 \%$ received free antituberculosis. Facilities (94.9\%) were not involved in the product selection as it was undertaken by providers. Also, $65.4 \%$ of the facilities received expiring drugs, $87.2 \%$ did not have well trained and efficient staff. In addition, $88.5 \%$ admitted that supplies were sometimes delayed and they (65.4\%) are usually not intimated of the reasons, $66.2 \%$ do not calculate average monthly consumption, $59.5 \%$ submit LMIS report monthly while $60.0 \%$ do not have inventory control system. The study indicated that stock out and supply interruptions still exist several years after FMoH survey and recommendations. This study found that logistic challenges still exist at the SDPs implying that either FMoH recommendations were not implemented or implementation was ineffective in addressing the challenges.
\end{abstract}

Keywords: inventory management, logistics, procurement and supply management, supply chain management

\section{INTRODUCTION}

A functional health system is one that ensures a sustainable and uninterrupted supply of efficacious, safe, and quality medicines to all end-users, especially the vulnerable population. Target $8 \mathrm{e}$ of the Millennium Development Goal was to "...provide access to affordable essential drugs in developing countries" and access is defined as "having medicines continuously available and affordable at public or private health facilities or medicine outlets that are within one hour's walk from the homes of the population" [1].
Ensuring sustainable availability of medicines requires effective supply chain of medicines.

Supply chain involves the activities to facilitate delivery of goods from manufacturer to the end user. An effective supply chain consistently ensures the availability of products at the delivery points with efficient supply and demand management. Supply chain is an interconnected system of organizations, people, technology, activities, information and resources functioning to ensure the effective delivery of a product from point of manufacture to point of delivery to the end user, in a cost-effective manner [2].

*Correspondence. E-mail: ndidi.ngwuluka@biodrudel.com Tel: +234-8100331517.

ISSN 0189-8442

(cc) BY-NC 2021. Published by Faculty of Pharmaceutical Sciences, University of Jos, Nigeria. Under Creative Commons Attribution-Non-Commercial 4.0 International License. https://creativecommons.org/licenses/by-nc/4.0/ 
Health supply chain comprises the series of activities vital to deliver and effectively provide uninterrupted supply of the right quality and quantity of medicines at the right location, cost and time. Supply chain management therefore is the organization and coordination of series of activities required for the delivery and effective provision of uninterrupted supply of the right quality and right quantity of medicines at the right time, to right location and to the right patients. A costeffective health supply chain is a two-way system which delivers health products to the end-user and also sends critical information such as need, demand and consumption to the health system planners [2].

Supply chain management is the backbone of operations and a detailed system employed by small and large organizations to ensure that products get to the end-users. However, supply chain management of health commodities in developing countries is weak and un-coordinated leading to poor service delivery and limited access to medicines. The underlining factors leading to this may include issues of transparency and accountability, uncertainties in financing, unnecessary level of complexity, long re-supply intervals, lack of interest in funding operating costs, lack of supply chain planning data, mismatch between skill and system design, and lack of incentives for supply chain staff [2].

Despite the reforms put forward to address the issues in the health system, effective implementation has remained a challenge. The Nigerian health system is fraught amongst others with inadequate personnel, weak logistics systems and poor service delivery. The Nigerian government has been supported by partners to improve health systems. Despite that, the report of Federal Ministry of Health (FMoH) partners' support survey in 2010 [3], indicated there were stock outs, expirations of products and procurement of medicines with short shelf lives. The FMoH survey was undertaken to map the support provided by several partners in medicines procurement and distribution. These partners supported the Nigerian public health sector with funds as well as technical expertise to improve the health systems. The partners included 8 multilateral, 8 bilateral and 7 nongovernmental organizations who at the time supported the procurement of medicines and other pharmaceutical supplies.

Some of FMoH findings include:

- The survey demonstrated that the procurement and supply of medicines was uncoordinated, fragmented, and unplanned.

- Product selection was mainly done within the organizations or by private agents contracted by the partners.

- While National Drug Policy requires that facilities which express need for a product should be supplied, the survey showed that some partners plan procurement internally and products are just sent to the recipients as such supply is not preceded by accurate quantification of need. Though HIV/AIDS medicines and supplies need quantification is handled by John Snow Incorporation (JSIDELIVER) and National AIDS and STIs Control Programme (NASCP), there was no evidence of systematic quantification of $\mathrm{TB}$ and antimalaria medicines.

- Only about half of the procurements were based on a procurement plan and only about $11 \%$ were based on the country's Essential Medicines List.

- Though the statutory role of Federal Medical Store (FMS) is to manage medicines, they were not involved in the distribution of most of the procured medicines and medical products. Only about $23 \%$ of procurements were distributed by national programs as most were distributed by privately contracted agents and the donors.

- Major effects of these challenges include stock outs, expirations of products and procurement of medicines with less than $80 \%$ shelf life. These may be attributed to inadequate political commitment on the part of government and/or partners, lack of structures and absence of procurement supply management plan to articulate the country's need and guide partners who intended to share burden with the government [3].

After the findings, the recommendations were:

- The government needs to take leadership in issues of procurement and supply management of all medicines and pharmaceutical supplies by establishing a functional working group to plan and 
implement Procurement and Supply Management (PSM) activities

- PSM plan needs to be developed to ensure that all requirements of the country are detailed, and partners are thus required to participate in implementation of the plan

- The National Policy on procurement of medicines and pharmaceutical supplies should be developed and disseminated to all partners to ensure conformity of current and future support to the country

- To ensure conformity to the National Medicine Policy requiring flow of medicines through the Federal Medical Stores, the warehouse should be refurbished into a modern warehouse which provides appropriate management and security of products. Zonal stores could also be developed to facilitate access to health facilities. However, all users of the stores should be required to contribute to its maintenance.

- A robust medicines and supplies management information system should be established using modern information technology to ensure flow of information to all stakeholders to support planning and implementation of the PSM system [3].

Effective supply chain of medicines is feasible with policies to facilitate and encourage best practices ensuring continuous availability of medicines and maximize resources. It was envisaged that after the $\mathrm{FMoH}$ findings and recommendations, efforts would have been made to improve on procurement and supply of medicines to ensure sustainable and uninterrupted availability and accessibility of medicines. Consequently, the logistics systems in some health facilities in Jos metropolis were assessed for the availability of medicines for HIV/AIDS, TB, and Malaria. The assessment of health facilities is an approach to determine the implementation of the recommendations. If the recommendations were implemented, there will be improvements at the service delivery points. This survey was targeted at examining the SCM of medicines for priority health diseases (HIV/AIDS, TB, and malaria) because these are the diseases that the Nigerian government receive major support (fund and technical expertise) from partners.

\section{EXPERIMENTAL METHODS}

Study design. Descriptive survey questionnaires were designed, tested, and administered by interview to obtain data for this study. The questionnaires were pre-tested at primary and secondary Health care facilities and modified appropriately before being used.

Study area/population. The study was undertaken in Jos North and Jos South Local Government areas of Plateau State, Nigeria; between November 2015 and February 2016. The study area had 71 facilities comprising 62 primary, 6 secondary and 3 tertiary Health care facilities. The targets or key interviewees were staff in-charge of procurement, dispensing, stores, and patients.

Sample size determination. Sample size was determined using an online sample calculator (Creative Research System sample size calculator) to be 52 facilities at $95 \%$ confidence level and $5 \%$ confidence interval.

Sampling technique. Seven secondary Health care facilities (public and faith-based) and 3 tertiary Health care facilities were included in the study. Primary Health care facilities were selected based on electoral wards in the two local governments. A total of 52 Health care facilities were visited and data collected from 40 of them. In twelve (12) facilities, officials to be interviewed were absent.

Data collection. Interviewer-administered questionnaires were employed to obtain data from the health care facilities. Six categories of interviews were conducted at each facility using target questionnaires. The identified Interviewees were Procurement Officers, Storekeepers, Dispensers, HIV/AIDS, tuberculosis, and malaria patients.

Ethical consideration. The questions were basically logistics related; consequently, ethical approvals and consents were not required as different facilities managed our request for interviews disparately. Consents to undertake survey in government owned 
primary health care centres were obtained from the office of the deputy director, primary health care Jos South and office of the director, primary health care Jos North. Verbal consents were given by the patients before administering of the questionnaires. The questions asked were mainly on logistics and therefore, was of no harm. Data were collected anonymously and so cannot be linked to any patient.

Data analysis. All data were generated on Microsoft Excel, coded and exported into Statistical Software for Social Sciences (SPSS) version 20.0 for descriptive analysis.

\section{RESULTS AND DISCUSSION}

Demography and distribution of participants and medicines. The distribution of the participants is shown in Table 1 and about $59.4 \%$ of the participants were health workers. Table 2 shows the demography of the health workers who participated in the study.

Figures 1 and 2 indicate the estimation and distribution of health facilities receiving free antiretroviral and anti-tuberculosis. However, $2.6 \%$ of the health facilities received the following drugs: abacavir oral liquid, zidovudine oral liquid, lamivudine and stavudine tablets.

The study indicated as shown in Table 3 that about $80 \%$ of the facilities received free antimalarials particularly sulphadoxinepyrimethamine and $82 \%$ procured subsidized antimalarials mainly artemether+lumefantrine. Table 4 displays the list of antimalarials available in the health facilities while Figure 3 shows the distribution of antimalarials stocked by the health facilities. Most patients claimed they had never received antimalarials from the facilities. One of the possible reasons may be that self-medication is rampant when symptoms of malaria are experienced. Patients do not necessarily visit clinic for such. Clinics are visited when self-medications proved ineffective. Patients visit the pharmacies to purchase antimalarials. Another reason is inadequate patient information/education. When patients visit some facilities and present their symptoms, they are given drugs and instructed on how to administer the drugs. They are neither told the cause of the symptoms nor the names of the drugs given to them. They may be given antimalarials and they would not know. However, HIV/AIDS and TB patients are more definite, and treatment is prolonged. Consequently, while some patients, mostly rural patients may not be certain of the names of the drugs given, they know the disease being treated. The suggested retail price for artemether+lumefantrine is one hundred and fifty (150) Naira; however, only $13.2 \%$ of the facilities sold at this price.

The survey indicated that the antimalarials anti-retrovirals and antituberculosis were dispensed by $87.5 \%, 48.1 \%$ and $26.4 \%$ of health workers (particularly dispensers and storekeepers), respectively. The trend correlates with the prevalence of these diseases in Nigeria, malaria being the most prevalent.

Table 1: Distribution of study participants $(n=187)$

\begin{tabular}{llcc}
\hline & Variable & Number & Percentage \\
\hline \multirow{4}{*}{ Patients } & HIV & 43 & 23.0 \\
& TB & 3 & 1.6 \\
& Malaria & 30 & 16.0 \\
& Total Patients & 76 & 40.6 \\
\hline \multirow{4}{*}{ Health workers } & Dispensing & 46 & 24.6 \\
& Procurement & 39 & 20.9 \\
& Store & 26 & 13.9 \\
& Total Health workers & 111 & 59.4 \\
\hline
\end{tabular}


N.C. Ngwuluka et al. / J. Pharmacy \& Bioresources 18(2), 133-146 (2021)

Table 2: Demography of health workers

\begin{tabular}{llcccc}
\hline Variable & $\begin{array}{c}\text { General } \\
\mathrm{n}(\%)\end{array}$ & $\begin{array}{c}\text { Procurement } \\
\mathrm{n}(\%)\end{array}$ & $\begin{array}{c}\text { Store } \\
\mathrm{n}(\%)\end{array}$ & $\begin{array}{c}\text { Dispensary } \\
\mathrm{n}(\%)\end{array}$ \\
\hline \multirow{3}{*}{ Educational } & Primary & $1(0.9)$ & - & - & $1(2.2)$ \\
Qualification & Secondary & $1(0.9)$ & - & - & $1(2.2)$ \\
& Post-secondary & $74(66.7)$ & $27(69.2)$ & $17(65.4)$ & $30(65.2)$ \\
& Degree & $34(30.6)$ & $12(30.8)$ & $8(30.8)$ & $14(30.4)$ \\
& Post degree & $1(0.9)$ & - & $1(3.8)$ & - \\
\hline \multirow{2}{*}{ Work Experience } & Less than 1 & $19(17.1)$ & $7(17.9)$ & $5(19.2)$ & $7(15.2)$ \\
(years) & $1-5$ & $62(55.9)$ & $23(59.0)$ & $15(57.7)$ & $24(52.2)$ \\
& 6 and above & $26(23.4)$ & $8(20.5)$ & $4(15.4)$ & $14(30.4)$ \\
\hline & Head & $51(45.9)$ & $27(69.2)$ & $15(57.7)$ & $9(19.6)$ \\
& Assistant Head & $11(9.9)$ & $4(10.3)$ & $2(7.7)$ & $5(10.9)$ \\
Position in & General duty & $19(17.1)$ & $2(5.1)$ & $2(7.7)$ & $15(32.6)$ \\
Health care & Lab technician & $3(2.7)$ & $1(2.6)$ & $1(3.8)$ & $1(2.2)$ \\
facility & Pharmacist & $10(9.0)$ & $5(12.8)$ & $4(15.4)$ & $1(2.2)$ \\
& Storekeeper & $11(9.9)$ & - & $2(7.7)$ & $9(19.6)$ \\
& IT student & $1(0.9)$ & - & - & $1(2.2)$ \\
& Dispenser & $4(3.6)$ & - & - & $4(8.7)$ \\
& Attendant & $1(0.9)$ & - & - & $1(2.2)$ \\
\hline SCM & Yes & $62(55.9)$ & $23(59.0)$ & $15(57.7)$ & $24(52.2)$ \\
training status & No & $49(44.1)$ & $16(41.0)$ & $11(42.3)$ & $22(47.8)$ \\
\hline
\end{tabular}

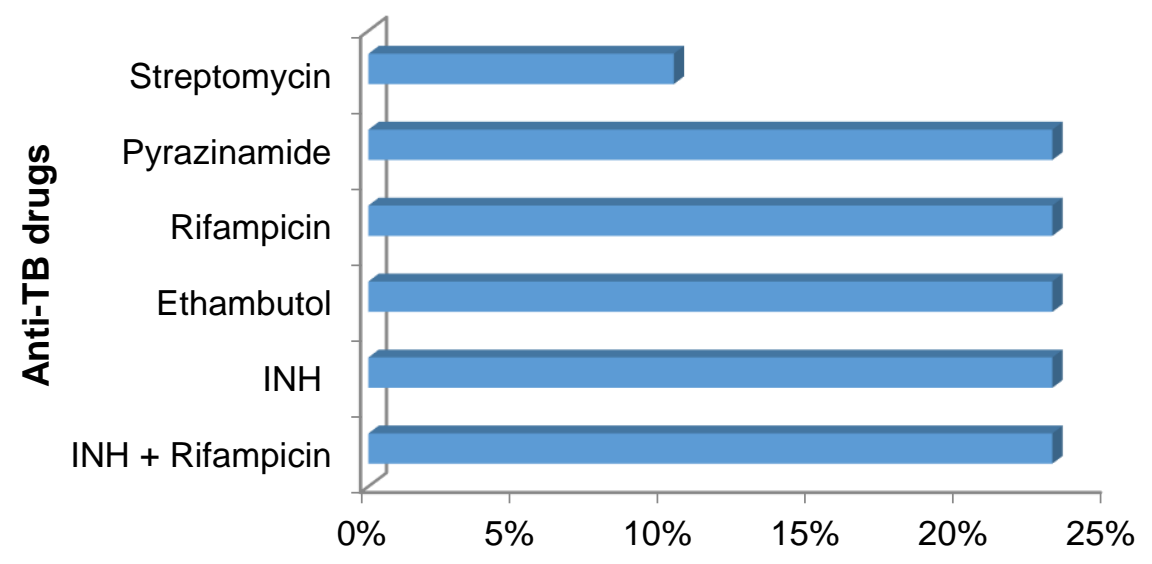

Precentage of facilities

Figure 1: Distribution of free anti-TB drugs

In the same order, Figure 4 shows the percentage of facilities that receive these drugs free with more facilities $(79.5 \%)$ receiving free anit-malarials. It is worthy to note that not all facilities are designated HIV or TB centres. This will imply that patients may have to move some distance to access medicines. However, due to stigmatization, some patients prefer to travel some distance to obtain their drugs.
Product selection, quantification, and procurement. Product selection precedes quantification and procurement, identifying products that should be quantified and procured. To make supply chain of medicines effective and efficient at health facilities, the variety of medicines selected and procured should be limited. Product selection promotes access to more affordable product prices through economies of scale and reduces the 
cost of supplies as larger quantities of fewer products are required [4]. This may explain why the free antimalarial products supplied are three - artemether + lumefantrine, artesunate + amodiaquine and sulphadoxine + pyrimethamine. The first two are used in the treatment of uncomplicated malaria which is common in Nigeria and the third is for intermittent preventive treatment in pregnancy. All antimalarials both free and procured by the facilities are recommended by WHO treatment guidelines [5] and in Nigeria's Essential Medicines List (EML). Most anti- retrovirals provided free to the facilities are listed in the EML while some drugs such as tenofovir and its fixed combination (Lamivudine + efavirenz + tenofovir) were neither listed in EML 2010 [6] nor EML 2016 [7]. This fixed combination was supplied to $43.6 \%$ of the facilities. Six years after FMoH survey and recommendations, some products supplied to the facilities do not conform to the EML. The regulations of the country require that products supplied conform to the country's EML.

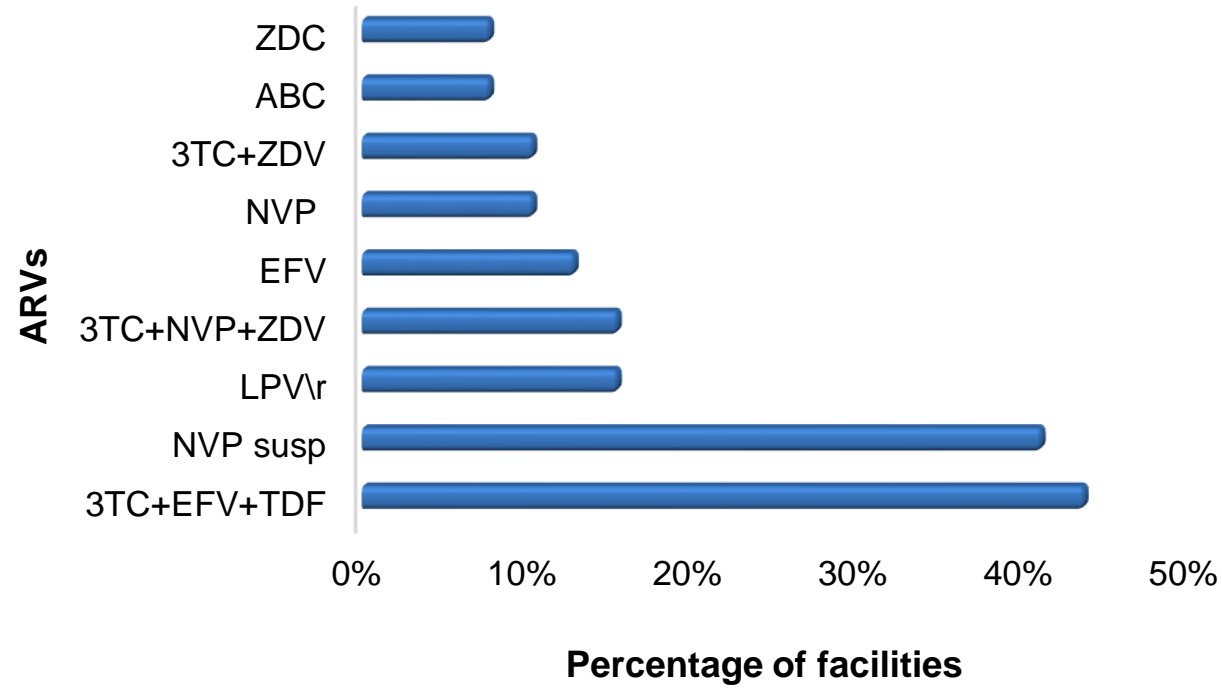

Figure 2: Distribution of free ARV (all are tablets except NVP susp) (ZDC - zidovudine; ABC - abacavir; 3TC - lamivudine; NVP - nevirapine; EFV - efavirenz; LPV $\backslash \mathrm{r}$ Lopinavir/ritonavir; TDF - tenofovir)

Table 3: Availability of antimalarials at 39 study sites: responses from procurement officers

\begin{tabular}{lcc}
\hline \multicolumn{1}{c}{ Variable } & Responses & n (\%) \\
\hline \multirow{2}{*}{ Received free antimalarials } & Yes & $31(79.5)$ \\
& No & $6(15.4)$ \\
\hline \multirow{2}{*}{ Type of free antimalarials } & Sulphadoxine +Pyrimethamine (SP) & $30(76.9)$ \\
& Artemether + Lumefantrine & $24(61.5)$ \\
& Artesunate + Amodiaquine & $13(33.3)$ \\
\hline \multirow{2}{*}{ Antimalarials was supplied last (in years) } & Less than 1 & $1(2.6)$ \\
& 2 & $1(2.6)$ \\
& 3 & $2(5.1)$ \\
Procuredlreceived subsidized & 6 and above & $1(2.6)$ \\
Antimalarials & Yes & $32(82.1)$ \\
Subsidized antimalarial procured & No & $4(10.1)$ \\
\hline
\end{tabular}


Table 4: List of available antimalarials at facilities obtained from 39 procurement officers and 30 Patients

\begin{tabular}{lcc}
\hline Antimalarials & $\begin{array}{c}\text { Procurement officers } \\
\mathrm{n}(\%)\end{array}$ & $\begin{array}{c}\text { No. of Patients } \\
\mathrm{n}(\%)\end{array}$ \\
\hline Artemether + Lumefantrine (AL) tablets & $30(76.9)$ & $17(56.7)$ \\
Artemether + Lumefantrine Oral liquid & $12(30.8)$ & - \\
Artesunate + Amodiaquine (AA) tablet & $11(28.2)$ & $1(3.3)$ \\
Artesunate + Amodiaquine Oral liquid & $3(7.7)$ & $1(3.3)$ \\
Artesunate + mefloquine tablet & $3(7.7)$ & - \\
Artesunate + mefloquine Oral liquid & $1(2.6)$ & - \\
Artesunate + Sulphadoxine + Pyrimethamine (SP) tablet & $1(2.6)$ & $1(3.3)$ \\
Dihydroartemisinin + piperaquine tablet & $2(5.1)$ & $1(3.3)$ \\
Mefloquine tablet & $2(5.1)$ & - \\
Mefloquine Oral liquid & $1(2.6)$ & - \\
Primaquine tablet & $1(2.6)$ & - \\
Proguanil tablet & $4(10.3)$ & - \\
Sulphadoxine +Pyrimethamine tablet & $25(64.1)$ & $7(23.3)$ \\
Sulphadoxine +Pyrimethamine Oral liquid & $4(10.3)$ & - \\
Quinine Tablet & $4(10.3)$ & - \\
Quinine injection & $21(53.8)$ & $1(3.3)$ \\
Artemether injection & $22(56.41)$ & - \\
Artesunate tablet & $13(33.3)$ & $2(6.7)$ \\
Artesunate Oral liquid & $4(10.4)$ & - \\
Artesunate Injection & $3(7.7)$ & - \\
Chloroquine tablet & $2(5.1)$ & - \\
Chloroquine Injection & $1(2.6)$ & - \\
$\alpha-\beta$ artemether injection & $1(2.6)$ & - \\
\hline
\end{tabular}

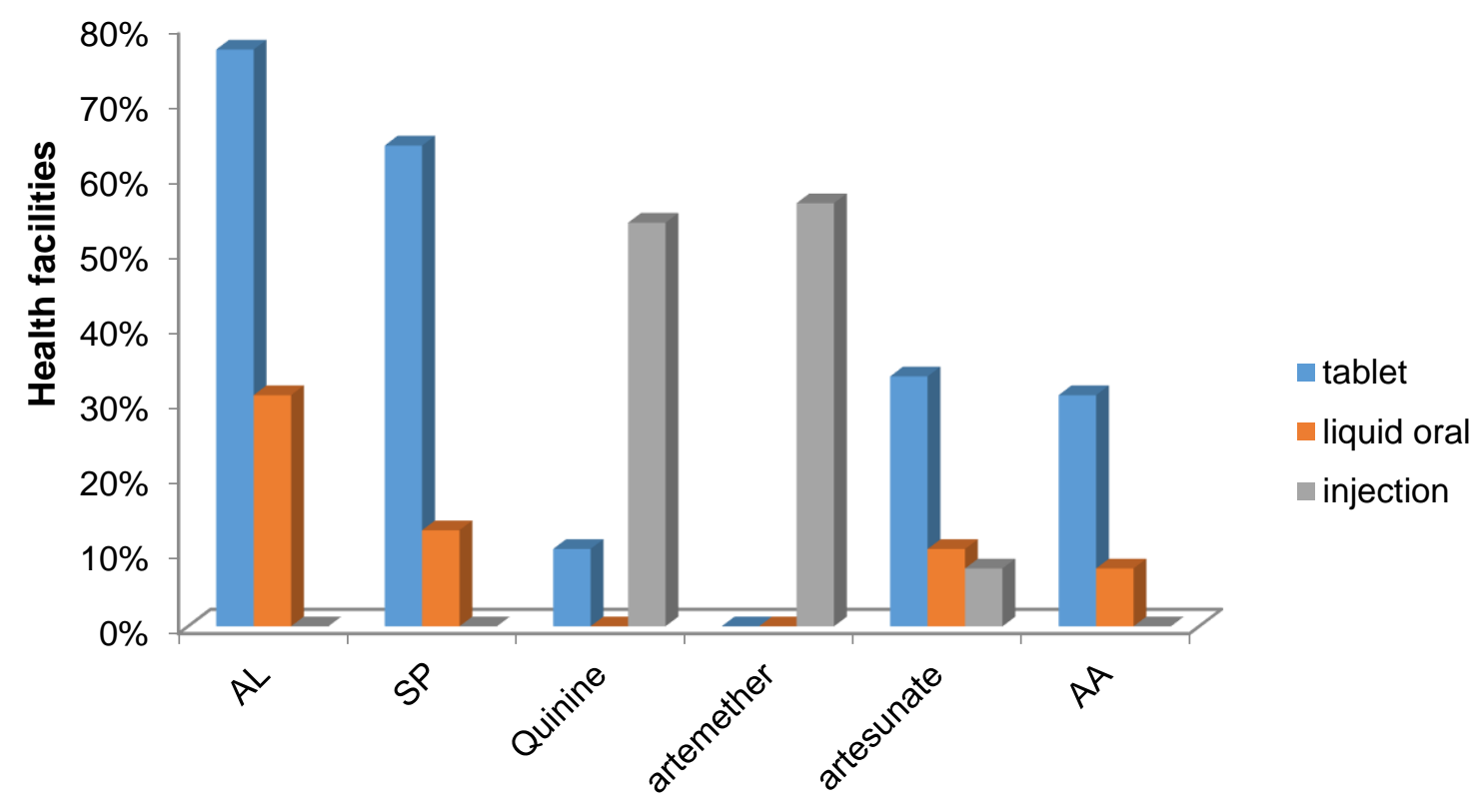

Antimalarials

Figure 3: Distribution of commonly stocked antimalarials at the health facilities 


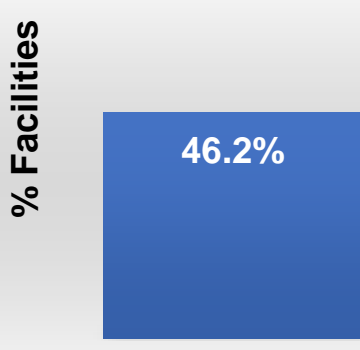

ARVs

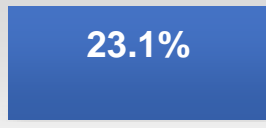

Anti-TB

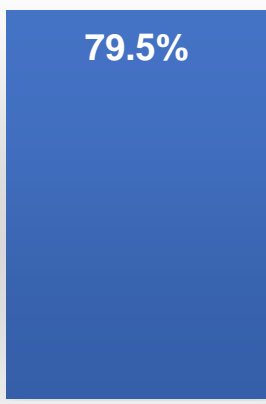

Anti-malarials

\section{Drugs}

Figure 4: The percentage of facilities receiving free drugs for priority diseases

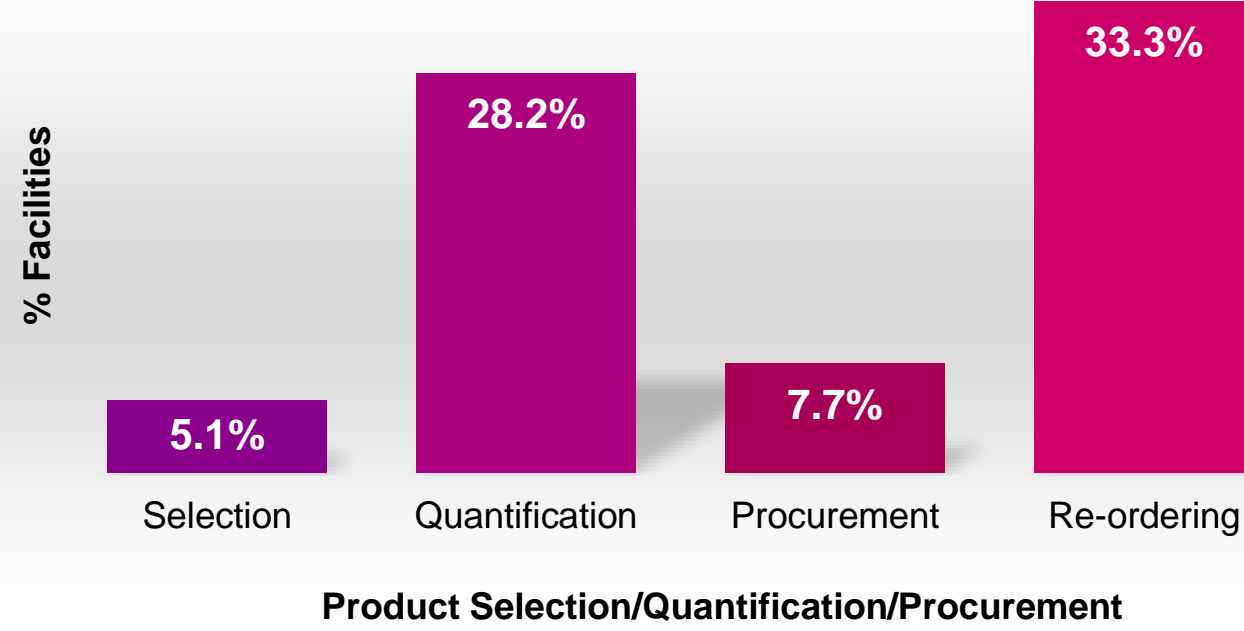

Figure 5: Level of participation of facilities in product selection, quantification, and procurement

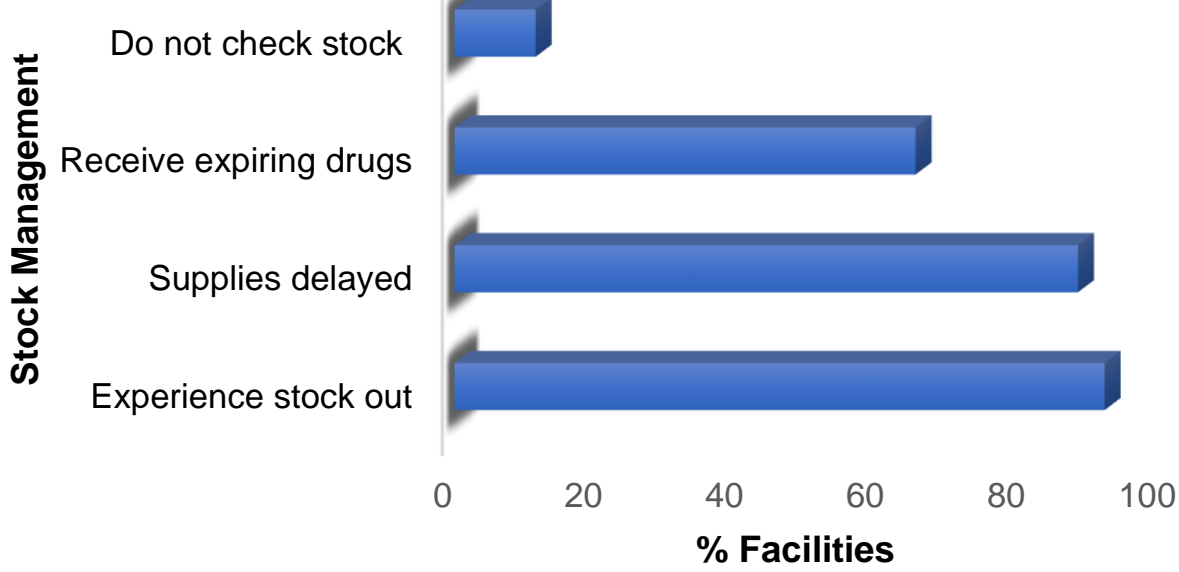

Figure 6: Performance of the health facilities on stock management 


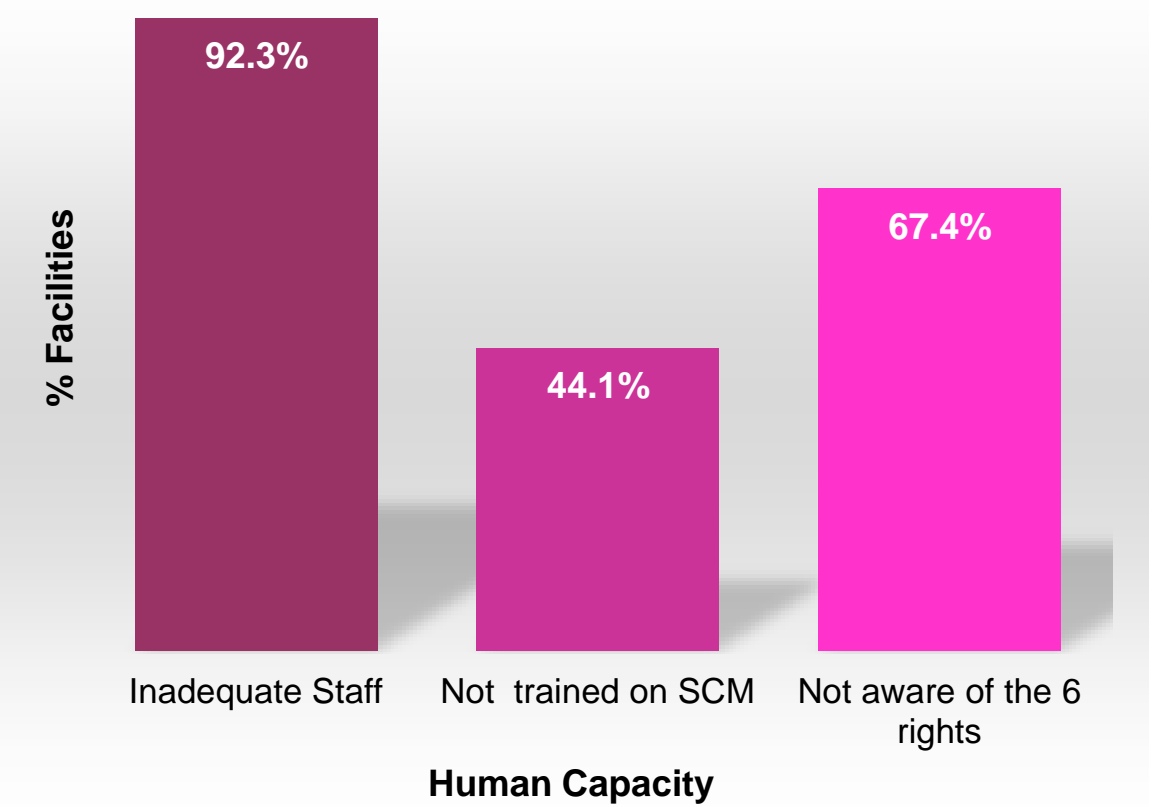

Figure 7: Assessment of capacity building

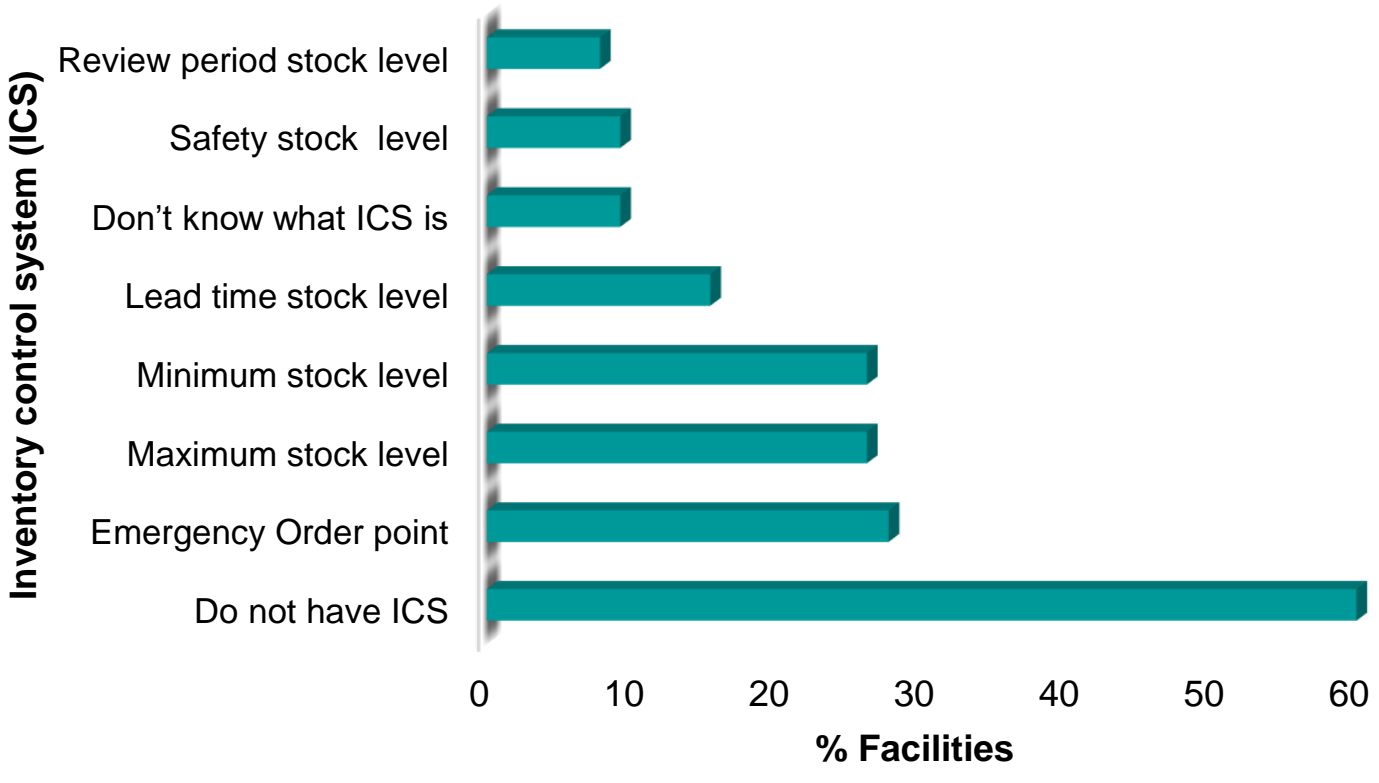

Figure 8: Performance of health facilities on inventory control system

However, the fixed combination is a strong recommendation as first line anti-retroviral treatment by WHO [8] and the guidelines for management of HIV/AIDS are reviewed more frequently than the EML. It is interesting to note however, that the fixed combination recommendation was in the 2010 National guidelines for HIV and AIDS treatment and care in adolescents and adults [9] and 2016 integrated national guidelines for HIV protection, treatment and care [10]. Yet, the EML 2016 did not have it. The national guidelines for HIV/AIDS dropped stavudine 
from the list of preferred regimens due to lipodystrophy associated with its use, and EML still has it listed. With regards to antiretroviral drugs, the two guidelines should be harmonized. The procurement and supply of anti-TB drugs conform to EML; however, streptomycin has been removed from the 2016 EML.

Quantification is undertaken to ensure that service delivery points have uninterrupted supply of medicines. Estimates of quantities and costs of products are determined as well as the periods of procurement and distribution. Quantification data are employed to maximize available resources for procurement, advocate for mobilization of additional resources when needed and inform manufacturer production cycles and supplier shipment schedules [4]. The three data required for quantification are consumption data, services data, and demographic data. The data gathered for quantification help to identify weak areas for interventions to be made.

The effectiveness of supply chain of the ARVs and anti-TBs were assessed by obtaining information on some essentials of logistics. Product selection, quantification, and procurement of ARVs and anti-TBs were said to have been undertaken by partners with little or no input from the Managers of health facilities. This is still as was observed by the FMoH survey which indicated that $87 \%$ of procurement was undertaken by donors and their privately contracted agents [3]. Indeed, the push system is in operation in most of the facilities. Figure 5 indicates the level of participation of the facilities in product selection, quantification, and procurement. Quantities re-supplied were determined by $23.1 \%$ of the facilities and $28.2 \%$ do not know how quantities delivered to them were calculated. While some were involved in reordering, partners just send products to $66.7 \%$ of the facilities without any input from them. Either pull or push system can be effective if the right data is transmitted at the right time to the right location for decision making. Drugs sent directly to some of the facilities may imply that Federal medical stores as recommended by $\mathrm{FMoH}$ report may still not be the sole channel of distribution. Over centralization makes effective management difficult especially in a large country like Nigeria where the public service is largely inefficient.

Storage/Stock Management/Assessment. A standard storage room should have sufficient space, acceptable storage conditions, explicit Quality Assurance (QA) mechanisms, adequate product security, and standard storage procedures to assure the physical integrity of the products thereby maximizing their shelf life. ARVs were stored by $57.7 \%$ and Anti-TB by $26.9 \%$ of the health facilities that participated. The stocking and storage of antimalarials were undertaken by $96.2 \%$. While $19.2 \%$ had separate stores for these drugs, $73.1 \%$ had separate shelves within a store for them. However, those with neither store nor shelves had cupboard within a personnel's office for the drugs. Receiving drugs different from those ordered were admitted by $11.5 \%$. Only $7.7 \%$ never experienced stock out. As an approach to manage 'stock outs' for ARVs and Anti-TB, $43.1 \%$ of the facilities dispensed substitutes. Also, when stock on hand would not meet demand, quantity dispensed to each patient was reduced in $22.2 \%$ of the facilities. Another approach taken by some facilities $(15.3 \%)$ was to borrow from other facilities. The facilities (43.1\%) occasionally do not have their requests fulfilled. For antimalarials, in some instances of 'out of stock', the facilities while they await the free supplies take the initiative to procure to meet demand and, in such cases, it may no longer be given to the patients free or subsidized. All storekeepers claimed they visually inspect all delivered products and $23.1 \%$ of the facilities had received damaged packages. 
Stock status were determined daily by $53.8 \%$, weekly by $34.6 \%$ and monthly by $15.4 \%$ and $11.5 \%$ do not check stock. Products with damaged package have been received by $23.1 \%$, damaged products by $19.2 \%$ and illegible information on the boxes/damaged boxes by $11.5 \%$. Water damaged cartons have been received by $19.2 \%$ and $65.4 \%$ have received almost expired products. Figure 6 shows the performance of the health facilities on some key elements of stock management. Stock outs may be due to error in quantification and forecasts of medicines and supplies, delay in delivery and insufficient transport facilities [3]. Then, 88.5\% alluded to the fact that drug supplies were delayed and $65 \%$ stated that the reasons for delay were not communicated while $11.5 \%$ stated that delay was usually due to logistics.

Actions taken on almost expired drugs included distributions amongst other facilities (50.0\%), discarded on expiry $(80.8 \%)$, dispensed until 3 months after expiry $(30.8 \%)$, dispensed until 6 months after expiry (34.6\%) and dispensed until exhausted (3.8\%). Some primary Health care facilities visited in December $2015 \quad$ received artesunate+Amodiaquine tablets with expiry date of the same month - December 2015. Drugs should not be used after expiry as the quality cannot be assured. Usually, transportation and storage conditions for the drugs are poor. In addition, the drugs are not sent for quality assessment. As a result, expired drugs may not be efficacious and may lead to drug resistance and compromised safety of patient. Receiving almost or already expired products does not only give concern about quality of products received but also suggest other logistical problems. Factors leading to expiration include poor medicine selection, forecasting, demand quantification, procurement, warehouse management, inventory management, employee training, use [11], poor transportation network and delays at the Nigerian ports [12].
Serving the user (Users' perspective). Patients admitted to being given free ARVs and anti-TB. Most (88.4\%) of whom receive ARVs every two months while those on antiTB $(6.5 \%)$ receive theirs every 2 weeks. Patients $(39.1 \%)$ have during treatment received less quantities of drugs; however, they stated that such was not frequent. They were usually informed to return earlier than usual having been given the explanation why they were not given the usual quantities. Some of the patients due to stigmatization register at facilities far from their residences and not getting the right quantities at the right time distorts their plans and may contribute to lack of compliance and drug resistance.

Also, $25.6 \%$ of them have experienced change of drugs and $18.6 \%$ were given reasons for the change of drugs. Reasons included drug resistance, delayed supply, and adverse drug effects. Only $6.5 \%$ have ever received medicines with damaged packages and $32.6 \%$ admitted to skipping their clinic days. With regards to counseling, $47.8 \%$ of patients claimed they did not receive counseling all the time, however all admitted they had opportunity to ask questions. Time lapse between prescription and receiving drugs were over 10 mins for $30.4 \%$ of the patients.

Human capacity. The procurement officers in the facilities $(87.2 \%)$ opined that they do not have adequately trained and efficient staff for effective management of logistics and $92.3 \%$ insisted that the available staff are overworked. However, $69.2 \%$ have been trained on supply chain management. Poor stock monitoring $(53.8 \%)$ and collection/data analysis $(57.7 \%)$ were alluded to inadequate staff by storekeepers. Also, $69.6 \%$ and $67.4 \%$ of the dispensers were unaware of the impact of right drugs and right quantities, respectively. The percentage of dispensers not trained on SCM was $89.1 \%$. It was observed that most of the personnel in the primary health care facilities apart for the head/manager in charge were not trained on SCM. However, 55.9\% of staff 
trained on SCM were mainly those from tertiary and secondary facilities. Figure 7 displays a key factor to ineffective supply chain management - inadequate and incompetent human resource. Some of the primary health care facilities utilized volunteers for dispensing of drugs. Inadequate staffing and training may remain a spanner in the works of health supply chain if not addressed by top management of health facilities. In some cases, inadequate staffing may be exaggerated and may require incentivization of staff for efficiency. Staff should be motivated to provide selfless services. In addition, working tools such as user-friendly Information Technology (IT) applications should be provided to cushion the work pressure and enhance efficiency. Capable personnel are crucial to the smooth running of health systems. The various aspects of the logistic cycle depend on personnel and as a result, training and retraining and equipping supply chain personnel are paramount. Focusing on improving the aspects of the logistic cycle without development of human resources will yield minimal progress in achieving functional health system.

Inventory management. One approach to ensuring the six rights of logistics is by holding inventory. Inventory management is a tactical approach to balancing supply and demand while operating efficiently and controlling cost. Inventory management practices are actions that govern the movement of inventory from manufacturer to the customer and the decisions and polices that determine which products to hold in inventory, how much to hold and where to hold it [13].

Data collected were consumption, transaction, and stock. The highest data collected was the consumption data $(93.7 \%)$; however, $66.2 \%$ of key personnel interviewed admitted that their facilities do not calculate average monthly consumption (AMC). AMC is used to determine stock status of a facility to determine when to order. Determining stock status ensures that a facility is not overstocked, understocked or at emergency point and stock status ought to be determined regularly. While the demand for HIV/AIDS and anti-TB drugs may be consistent and so the usual last three months of consumption data may be used to determine AMC, antimalarial drugs have their peak and valley demands. Consequently, for antimalarials, AMC may be calculated using last 6 months, last 12 months, previous month or the last year's consumption data for the same three months [4].

The facilities (87.7\%) had Logistics Management Information System (LMIS) forms - stock on hand, quantity used and losses and adjustment. About $73.9 \%$ of the interviewees learnt to complete LMIS forms at a workshop and $26 \%$ learnt on the job. While $51.5 \%$ and $30.5 \%$ submit LMIS forms monthly and bi-monthly respectively, $14.8 \%$ have never submitted to implementing partners and only $23.1 \%$ get regular feedback on report submitted. Generating and maintaining a robust LMIS is crucial in ascertaining that the overall supply chain can be strengthened [4]. Figure 8 show the $\%$ response of the facilities on inventory control system. It was observed that $60 \%$ of the facilities did not have an inventory control system and some that had admitted it was not running smoothly. An inventory control system is used to determine when to order or issue, how much to order or issue and how to maintain an appropriate stock level of all products to prevent shortages and oversupply in health facilities [13]. With regards to $\mathrm{FMoH}$ recommendation of management information system, while progress has been made, inefficiencies still exist. This is indeed an area for improvement in the health facilities. Inventory management is considered a critical global health supply chain issue [11]. Inventory management issues include inventory inaccuracies, quantification, uninformed push systems, inventory allocation, product availability management, and appropriate IT systems [11]. Assessing 
inventory performance can enhance inventory efficiency, customer service, effective planning, and appropriate use of resources such as finance.

Supervision. Regular monitoring, supervision and periodic evaluation are vital to ascertain the performance of the logistic system, determine areas that require improvement and the system's impact on service provision [4]. Generally, supervision was not regular, $49.5 \%$ of the facilities were supervised when there was a need and only $14.4 \%$ were supervised monthly. About $35.4 \%$ of the facilities did not experience changes after supervision. For there to be effective logistic system, there must be regular supervision. The limited supervision may be one of the factors leading to the weak areas identified. Had there been regular supervision, capacity of workers would have been monitored, on the job-training could have been employed to address some logistic issues, challenges faced by the facilities would have been communicated and addressed, reports would have been frequent and service to the user would have been enhanced. Monitoring and evaluation (M\&E) of performance of personnel and facilities determine the success or otherwise of every project or program in Nigeria. It requires personnel commitment and huge financial investment. Apart from international M\&E activities that are periodic, regular weekly and/or monthly activities are required.

Finance. Transportation of drugs is funded by the facilities $(56.4 \%)$ and $17.9 \%$ funded the sending of reports and $30.8 \%$ claimed there was no financial allocation.

Conclusions. This study found that logistic challenges still exist several years after $\mathrm{FMoH}$ survey and recommendations at the Service Delivery Points (SDPs) implying that either $\mathrm{FMoH}$ recommendations were not implemented or implementation was ineffective in addressing the challenges. It may also be that there was no specific timeline action plan for implementation and follow up. It is apparent that lack of planning is one of the challenges facing supply chain management of medicines. Consequently, inefficiencies in transportation, stocking, deliveries, and distributions are observed. There is limited investment in logistics systems and processes. At the service delivery points, supply chain is not running smoothly due to factors such as inappropriate allocation of resources, inadequate staffing, poor record keeping, noncompliance by some patients, corruption, loose policies. A procurement and supply management (PSM) plan must be developed and executed as recommended by the $\mathrm{FMoH}$ report. A robust management information system should be institutionalized, and personnel adequately trained to ensure flow of information amongst stakeholders to facilitate planning and execution which ensure a functional health system.

Several goals of health facilities competing for scarce resources - financial, human, and technical goals. There are such demands on limited resources; however, a well-designed logistic system is crucial for continuous availability of essential medicines in the health facilities. Effective logistic system requires prompt and efficient movement of products and information through the system. Consequently, specific guidance and guidelines must be developed and implement for LMIS, inventory control system, distribution, and storage. While it is important to improve the various aspects of the supply chain management cycle for partnership programs, it may be surface solution which implies that the challenges will continue to resurface until the underlining factors that give rise to dysfunctional health system are dealt with through effective health policy and implementation at all levels of Government. 


\section{REFERENCES}

1. MDG Gap Task Force Delivering on the Global Partnership for Achieving the Millennium Development Goals. United Nations, New York. 2008. https://www.who.int/medicines/mdg/MDG8English Web.pdf Accessed 27 ${ }^{\text {th }}$ Feb 2018

2. Yadav, P. Health product supply chains in developing countries: diagnosis of the root causes of underperformance and an agenda for reform. Health Systems \& Reform 2015, 1, 142-154.

3. Federal Ministry of Health Mapping of Partners' Procurement and Supply Management Systems for Medical Products. 2010. http://digicollection.org/hss/documents/s16889e/s16 889e.pdf Accessed 27 $7^{\text {th }}$ Feb, 2018.

4. USAID; DELIVER PROJECT, Task Order 3 Guidelines for Managing the Malaria Supply Chain: A Companion to the Logistics Handbook; USAID | DELIVER PROJECT, Task Order 3: Arlington, Virginia, 2011. http://ghsupplychain.org/sites/default/files/2019. 07/GuidManaMalariaSC_0.pdf Accessed $28^{\text {th }}$ Feb 2018.

5. World Health Organizationl. Guidelines for the treatment of malaria. $3^{\text {rd }}$ Edition. World Health Organization: Geneva, Switzerland, 2015. https://apps.who.int/iris/bitstream/handle/10665/162 441/9789241549127 eng.pdf;jsessionid=0FB49A4C BFEE40DE3D24D5DE67C8EA28? sequence $=1$ Accessed $28^{\text {th }}$ Feb 2018

6. Federal Ministry of Health Essential Medicines List. $5^{\text {th }}$ Edition. Federal Ministry of Health: Abuja, Nigeria, 2010. http://digicollection.org/hss/documents/s19018en/s1 9018en.pdf Accessed $1^{\text {st }}$ Mar 2018.

7. Federal Ministry of Health Essential Medicines List; $6^{\text {th }}$ Edition. Federal Ministry of Health: Abuja,
Nigeria,

2016. https://www.medbox.org/pdf/5e148832db60a2044c2 d35d1 Accessed 1 ${ }^{\text {st }}$ Mar 2018.

8. World Health Organization Consolidated Guidelines on the Use of Antiretroviral Drugs for Treating and Preventing HIV Infection: Recommendations for a Public Health Approach; World Health Organization: Geneva, Switzerland, 2013. https://apps.who.int/iris/bitstream/handle/10665/208 825/9789241549684_eng.pdf?sequence=1\&isAllowe $\mathrm{d}=\mathrm{y}$ Accessed $2^{\text {nd }}$ Mar 2018.

9. Federal Ministry of Health National guidelines for HIV and AIDS treatment and care in adolescents and adults; Federal Ministry of Health: Abuja, Nigeria, 2010.

https://www.who.int/hiv/pub/guidelines/nigeria_art.p df Accessed $2^{\text {nd }}$ Mar 2018.

10. Federal Ministry of Health. Integrated national guidelines for HIV prevention, treatment, and care: Chapters 5 and 6. J HIV Hum Reprod 2015, 3, 47-55.

11. Privett, N.; Gonsalvez, D. The top ten global health supply chain issues: Perspectives from the field. Operations Research for Health Care 2014, 3, 226230.

12. Olayinka, C. NLC, others decry non-release of antiHIV drugs from ports. The Guardian 23 November 2017. https://guardian.ng/news/nlc-others-decry-nonrelease-of-anti-hiv-drugs-from-ports/ Accessed $3^{\text {rd }}$ Mar 2018

13. John Snow, I. The Supply Chain Manager's Handbook, A Practical Guide to the Management of Health Commodities; John Snow, Inc: Arlington, Virginia, 2017. http://supplychainhandbook.jsi.com/wpcontent/uploads/2017/02/JSI_Supply_Chain_Manage r\%27s_Handbook_Final-1.pdf Accessed $3^{\text {rd }}$ Mar 2018. 